\title{
LIÇÕES DE UM AMIGO: CARTAS DE DRUMMOND A ZILA MAMEDE
}

\author{
Charliton José dos Santos Machado ${ }^{1}$ \\ Maria Lúcia da Silva Nunes ${ }^{2}$ \\ Larissa Meira de Vasconcelos ${ }^{3}$
}

\begin{abstract}
Resumo
Este texto convida o leitor a mergulhar na leitura de cartas do poeta Carlos Drummond de Andrade para a também poeta paraibana Zila da Costa Mamede ${ }^{4}$, entre os anos de 1953 e 1985. São dezenove missivas, onze bilhetes e um cartão acrescido de um telegrama. No contato e leitura dos 31 textos de correspondências, mais do que um movimento de voyeurismo com a escrita de dimensão individual e privada, buscou-se, neste estudo, compreender os elos da formação de uma escrita, tendo sido Drummond, certamente, ao lado de outros grandes nomes, personagem fundamental e decisivo nesse processo ao longo de três décadas.
\end{abstract}

Palavras-chave: Drummond. Zila Mamede. Formação. Escrita.

\section{LESSONS FROM A FRIEND: DRUMMOND LETTERS TO ZILA MAMEDE}

\begin{abstract}
This text invites the reader to dive in the reading of letters from the poet Carlos Drummond de Andrade to the paraibana and also a poet Zila da Costa Mamede between the years 1953 and 1985. There are nineteen missives, eleven notes and a telegram added to a postcard. In the contact and reading of the 31 texts of correspondences, more than a voyeurism movement with the writing of a personal and private dimension, it was sought, in this study, to understand the links of formation of a writing, with Drummond being, certainly, by the side of other great names, a fundamental and decisive character in this process throughout three decades.
\end{abstract}

Keywords: Drummond. Zila Mamede. Formation. Writing.

\section{LECCIONES DE UN AMIGO: CARTAS DE DRUMMOND A ZILA MAMEDE}

\section{Resumen}

Este texto invita al lector a sumergirse en la lectura de cartas del poeta Carlos Drummond de Andrade para la también poeta paraibana Zila da Costa Mamede, entre los años 1953 y 
1985. Son diecinueve misivas, once entradas y una tarjeta más un telegrama. En el contacto y lectura de los 31 textos de correspondencia, más que un movimiento de voyeurismo con la escritura de dimensión individual y privada, se buscó, en este estudio, comprender los eslabones de la formación de una escritura, habiendo sido Drummond, ciertamente, al lado de otros grandes nombres, personaje fundamental y decisivo en ese proceso a lo largo de tres décadas.

Palabras clave: Drummond. Zila Mamede. Formación. Escritura.

\section{PRIMEIRAS PALAVRAS...}

Este estudo intenta mergulhar na leitura de cartas do poeta Carlos Drummond de Andrade para a poeta paraibana Zila da Costa Mamede ${ }^{5}$, entre os anos de 1953 e 1985. São dezenove missivas, onze bilhetes e um cartão acrescido de um telegrama que vieram à baila em 2000, sob a iniciativa e organização da professora Graça Aquino (2000), publicadas de forma inédita pela editora Sebo Vermelho de Natal/RN.

Além da troca de experiências poéticas e diálogos cotidianos diversos, o acervo também documenta e registra de forma concisa os traços de uma fecunda orientação drummondiana voltada à formação da escritora, certamente, com evidente repercussão e influência em sua obra nesse efervescente cenário histórico, época em Zila começava alcançar reconhecimento local e nacional, com o livro de estreia, "Rosa de Pedra", publicado pela Imprensa Oficial do Rio Grande do Norte e acolhido de forma efusiva pela crítica.

A leitura de cada correspondência remete ao gosto criador da palavra como instrumento de ação afirmativa, dos aconselhamentos e lições do autor da "Rosa do Povo" (1945), principalmente, uma prática cultural relacionada à poesia em sua dimensão discursiva de operosa criação, fazendo assim, comunicar-se a partir das suas impressões pessoais (EU) Drummond, com a sensibilidade poética da destinatária (OUTRA) Zila Mamede.

Nos intensos diálogos são inúmeros os momentos por ele dedicados ao reconhecimento e à análise do estilo inovador da escrita mamediana no ambiente da chamada "Geração Pós-45". Ou seja, reconhecendo em Zila uma personagem capaz de ultrapassar tais limites, “[...] a ser a poeta que admiramos." (DRUMMOND, 1964 apud AQUINO, 2000, p. 19). Conforme ela própria admitiu à época, a palavra era considerada "[...] muito mais do que uma coisa escrita, tinha uma carga enorme de significados." (MAMEDE, 1987, p. 28).

Portanto, as missivas se constituem num valioso documento histórico, como fonte/objeto e, certamente, uma contribuição significativa à compreensão da formação de Zila Mamede, mulher intelectual, educadora, bibliotecária e poeta, ensejando, talvez, uma 
nova leitura sobre a sua obra, cuja narrativa dialógica este artigo se propõe como tarefa refletir e analisar.

\section{CARTAS: PRÁTICAS DE ESCRITAS, OBJETO DA MEMÓRIA}

Desde os anos de 1960, pesquisadores das ciências sociais, principalmente, historiadores, têm se debruçado sobre novas fontes de investigação no universo da cultura, num movimento de valorização das múltiplas atividades escritas, possibilitando assim a reconstrução das maneiras de pensar e agir de outras épocas.

Após, sobretudo, a denominada “[...] revolução documental [...]” (LE GOFF, 1990, p. 2003), a palavra "documento" passou a ter sentido lato, não se restringindo às fontes da história tradicional-político-militar. Ampliou-se, portanto, a concepção de documento para tudo aquilo que o ser humano produz no seu tempo. Isto é, todo e qualquer vestígio produzido pelos homens que deixaram marcas das relações existentes nas sociedades humanas. A objetividade científica, afinal, está muito mais próxima da formulação do problema e do cuidado com o manejo das ferramentas empregadas para respondê-lo, do que no tipo de fonte adotada.

Chartier (1990) advoga que esse novo olhar sobre escritos cotidianos reveste-se de grande importância, na medida em que se coloca na dimensão dos desafios de uma História Cultural que tem por principal justificativa entender como em diferentes lugares e momentos, uma determinada realidade é construída, pensada, dada a ler.

Nesse ínterim, ganhou importância os estudos sobre as correspondências entre intelectuais, políticos, educadores, artistas, militares, etc., para se pensar e entender uma leitura individual e/ou coletiva sobre rumos de acontecimentos, registrando assim impressões e memórias de cada personagem num dado tempo histórico.

Para Perrot (2008), ao se trabalhar com essa fonte, produto de uma memória da interrelação entre duas ou mais pessoas, cabe ao pesquisador entender que não há nada menos espontâneo, pois, além de se constituir de um prazer, uma licença, pode, ao mesmo tempo, ocultar ou desvelar acontecimentos históricos. Afinal, trabalhar com documentos epistolares implica em, necessariamente, ampliar a percepção do passado, multiplicando a maneira de acessá-lo por um ângulo imprevisto.

Sobre essa questão, Gondra (2003) ressalta que a prática epistolar foi se firmando como um instrumento de luta de educadores, “[...] o gesto de escrever, individual ou organizadamente, voltando-se não apenas para modalidade das correspondências privadas, de caráter pessoal, mas também para cartas dirigidas às autoridades [...]" (GONDRA, 2003, p. 17). 
Nesse particular, passaram a ser reconhecidas como parte da leitura íntima ou códigos específicos para se desvendar acontecimentos de uma época. Ou seja, como uma das ricas formas de permitir que as pessoas falem ao presente com a sua própria voz interpretativa sobre os mais diversos acontecimentos do passado. (BARMAN, 2005), constituindo-se em documento precioso e encantador, à "[...] medida em que se apanham as condições de sua produção, seus conteúdos e seus efeitos." (GONDRA, 2003, p. 31).

Por outro lado, em sua condição histórica, as missivas como fonte podem informar, mas, também confundir, posto que se trata de um documento pessoal capaz de guardar ou perder o significado de uma memória registrada em um tempo vivido. (LUCAS \& RAMOS, 2013, p. 07). Assim, como qualquer fonte histórica, faz-se necessário "[...] deixá-las falar e, do mesmo modo, resistir as suas armadilhas." (GONDRA, 2003, p. 32). Sua utilização requer atenção, pois " [...] a carta é um documento datado e assinado, todavia não é um documento livre de qualquer estratégia ou máscara social.” (BOAVENTURA, 2008, p. 104).

Destarte, Gomes (2005, p. 19) entende que, “[...] a correspondência constitui [...] o sujeito e o seu texto", indicando assim uma ação discursiva da escrita de si, numa vigorosa manifestação de dimensão (auto) biográfica. E sobre a experiência e tradição epistolar, Marques (1997) ressalta o caráter aventureiro dessa prática cultural, ou seja, uma espécie de ofício da vida cotidiana que busca no outro um sentido de existência:

Ao escrevermos uma carta visamos a um destinatário previsto [...] Apenas deles podemos visualizar certos traços comuns, certamente insuficientes para nossa ambição de controlar os efeitos do nosso escrever. Desta maneira, não podemos fugir ao caráter sempre aventureiro de tal empreitada. (MARQUES, 1997, p. 21).

Como documento histórico, as cartas, além de nos apresentarem referências a um tempo e um espaço determinados, permitem-nos adentrar, análogo a um voyeur ${ }^{6}$, em uma gramática interlocutiva que pode desvendar intimidades, segredos, estilos, formações, concepções, disputas hegemônicas nos campos a que pertencem os missivistas, trazendo à baila vestígios de uma experiência pessoal e cotidiana.

Nesse movimento, tal qual ocorre entre Drummond e Zila, busca-se uma aproximação efetiva (às vezes, afetiva) entre quem escreve e lê, ou seja, um ato cotidiano que se constitui numa ação de aventura dialógica entre produção e recepção das missivas, na harmonia da expressão do sentir com o pensar. De acordo com Veronez (2015, p. 203)

Uma característica marcante e própria deste tipo de prática de escrita das cartas é a capacidade que o "eu" epistolar (quem escreve) tem de se tornar presente e/ou ausente para o seu interlocutor (quem lê), num movimento racionalizado, recortado e interessado [...].

De acordo com Camargo (2000, p. 204), mais do que qualquer evidência de uma troca comum em que se enlaçam "[...] autor-escritor, escriba e destinatário-leitor", as escritas epistolares delimitam lugares e momentos particulares na história dos sujeitos interlocutores 
de uma cultura letrada. Por isso, “[...] podem ser guardadas pelo destinatário, como um bem de valor afetivo, incomensurável, como um objeto de memória." (GOMES, 2005, p. 07).

Silva (2002) insiste também que, além de se constituir como importante acervo histórico, a escrita pessoal tem em sua essência uma função sociomunicativa, que faz dela uma prática cultural de produção de linguagem, socialmente situada e capaz de engendrar uma forma de interação particular, provocadora e desafiante.

Nesse sentido, ao se revistar as correspondências de Drummond a Zila, constata-se um ambiente intelectual de trocas de impressões, ideias, episódios, testemunhos, confidências, fatos e, sobretudo, a cumplicidade sobre as maneiras de pensar e discorrer sobre a formação da escrita poética. Uma aventura histórica de leitura social do tempo vivido.

Portanto, através das correspondências é possível identificar como se instaura um ambiente intimista de registros ou testemunhos pessoais e mútua revelação entre o EU (Drummond) e o OUTRO (Zila Mamede), demarcando práticas de escrita de reciprocidade no campo de elaboração da poesia.

\section{CARTAS DE DRUMMOND A ZILA ${ }^{7}$ : PEDAÇOS DE UMA VIDA BEM ESCRITA}

"Zila querida, sua carta foi como ter você aqui ao lado, a gente no deslizar de um papo descansado, tão gostoso." (DRUMMOND, 1975 apud AQUINO, 2000, p. 49).

O fragmento da correspondência acima identifica a profícua e amigável relação construída entre Carlos Drummond de Andrade e Zila da Costa Mamede, iniciada ainda nos idos dos anos de 1950, algo que se intensificou em cada correspondência, encerrada somente em 13 de dezembro de 1985, em face da trágica morte da escritora paraibana, nas águas da Praia do Meio, próxima ao Forte dos Reis Magos, em Natal, capital do Rio Grande do Norte.

Em entrevista concedida à TV Universitária em 03 de fevereiro de 1981, Zila Mamede desvelava um momento particular de sua angústia existencial e intelectual, marca do seu estilo rigoroso e potencialmente autocrítico e do contato de aprendizagem construída com o poeta Drummond nessa conjuntura:

[...] escrevia daqui, escrevia dali, e um dia reuni do jeito que estava tudo que eu tinha rascunhado, rasurado (lembro que tinha em um dos poemas um palavrão, que escrevi comigo mesmo ou com o poema), e mandei para ele. (MAMEDE, 1987, p. 23).

A relação entre Drummond e Zila, conforme preconiza Aquino (2000, p. 09), estabeleceu um ambiente de trocas de experiências, cabendo ao primeiro o papel de educador “[...] no processo criativo." Os primeiros passos dessa relação são registrados em 18 de 
dezembro de 1953: "[...] meu melhor agradecimento pela oferta de 'Rosa de Pedra', que encerra uma poesia sensível e requintada." (AQUINO, 2000, p. 15). Sobre esse contato inicial da relação e troca de missivas, Zila informava em entrevista à TV Universitária a opinião de Drummond acerca da sua obra. Ele disse que "[...] eu não queria bem aos meus poemas e transformava naquilo que ele sabia, tinha absoluta certeza de que eu era capaz de fazer." (MAMEDE, 1987, p. 17).

O citado livro de estreia, com a impressão de apenas 200 volumes, foi considerado uma obra de renovação poética nacional e, segundo Alves (2006), já compunha a lista de obras dos estreantes jovens poetas que surgiam na literatura moderna brasileira, denominados nomes da controversa "Geração de 45 " e que se contrapunha à estética do Modernismo de 22. De acordo com o crítico literário Paulo de Tarso Correia de Melo, por isso mesmo, "Rosa de Pedra" trata-se de "[...] um digno livro de estréia." (MELO, 1978 apud MAMEDE, 1978, p. 15).

Nessa década de 1950 o impulso criador de Zila se revelaria em outras duas grandes produções poéticas: "Salinas", publicado em 1958 pelo Departamento de Imprensa Nacional do Ministério da Educação e Cultura e "O Arado", publicado no Rio de Janeiro pela Livraria São José em 1959. Em carta datada de 20 de maio de 1958, Drummond acentuava o valor dessa produção:

Zila amiga, que posso dizer dos seus poemas novos senão a verdade, isto é, que eles são uma beleza? O milho novo desabrochando páscoas, a dor do menino sacudindo miragens do pão, e as invenções da luz, da ventania: obrigado, Zila, por estes régios presentes de poeta. (DRUMMOND, 1959 apud AQUINO, 2000, p. 19).

Ainda sobre a obra "O Arado", Câmara Cascudo corroborava com a leitura drummondiana e fazia a seguinte menção: "Os poemas são frutos da terra e das almas poéticas que vivem em Zila Mamede.” (CASCUDO apud MAMEDE, 1978, p.178).

Na missiva de 27 de março de 1959, Drummond revela mais um momento de ensinamentos com o exercício permanente da palavra. Em tom amigável, o poeta aponta "provocações" de aprendizagens significativas, ao traçar sua leitura das páginas datilografadas da obra "O arado", lançada naquele ano:

Passei esta tarde de sexta feira lendo seus poemas e catando defeitos neles, para ser agradável a vosmecê, mas no fim as qualidades eram tão maiores e tão agradáveis de se perceber, que o caráter odioso da tarefa foi se dissipando, e ficou só a alegria de ver você crescendo em poesia. "O rio" e o primeiro soneto do "Os bois dormindo" são duas coisas de grande classe, e versos espalhados por todo o livrinho se impõem como unidades belíssimas [...]. (DRUMMOND, 1959 apud AQUINO, 2000, p. 23). 
Em missiva anterior, Drummond também já se coloca como parceiro, amigo e interlocutor da poeta na resolução da publicação da obra "Salinas" junto ao Departamento de Imprensa Nacional:

[...] subi ao $9^{\circ}$ andar e falei ao Simeão ${ }^{8}$. Ele riu muito, contou-me os sustos que tem passado em você, dizendo-lhe que o livro não sairá tão cedo, de castigo. A verdade é que o livro está quentinho no forno, segundo ele próprio Simeão, e Lúcia, a eficiente secretária, confirmou. Disse ela que as terceiras provas já seguiram para a Imprensa Nacional, com o “imprimatur", está bom? Se demorar apesar de tudo isso, irei novamente ao S. D. e me converterei no seu representante legal, clamando e reclamando providências. Mas acho que a coisa agora vai, Zila [...]. (DRUMMOND, 1958 apud AQUINO 2000, p. 19).

Em tom "professoral" de orientação, Drummond vai indicando suas anotações e sugestões de escrita, mesmo reconhecendo o quão árdua é a tarefa de leitura crítica de uma obra de outro poeta:

Bem, o que fui anotando a lápis é matéria para você pensar, e aceitar ou não, com a liberdade absoluta, e como lhe parecer razoável. Tenho maior constrangimento em propor qualquer modificação a um poeta, cada um é dono de seus erros e acertos, e receio ainda sugerir o que é apenas minha verdade, uma verdade precária mesmo nos limites do meu ser, que tenho mudado tanto ao logo da vida, e me substituo conforme o humor de cada hora. (DRUMMOND, 1959 apud AQUINO, 2000, p. 24).

Dadas as devidas ponderações e o "constrangimento" inicial destacado na missiva, Drummond não se esquiva do papel de amigo leitor e, sobretudo, crítico de uma obra poética relevante, na condição árdua e sempre desafiante tarefa de análise e contribuições:

\begin{abstract}
Noto o seguinte: certa repetição de palavras chave, como pasto, lírio, trigal, pão, que torna monótono o livro, embora a unidade temática imponha essa monotonia como condição prévia. Também gostaria de certas audácias, como transformar substantivos em adjetivos, ou compor palavras misturando as existentes, mas deixando claro para o leitor o elo que as prende. O mais é técnica de economia; cortar palavrinhas desnecessárias (o, um, seu), encurtar, acelerar, tornar mais direta e violenta a dicção. De importante não vejo nada a censurar. E o livro saiu uma doçura rural completa, uma coisa de terra e vida incorporada à terra, que torna autêntica sua poesia. É só, amiga Zila [...]. (DRUMMOND, 1959 apud AQUINO, 2000, p. 24).
\end{abstract}

Sustentado nessa condição de experiente escritor, tradutor e poeta de reconhecimento nacional, Drummond vai pontuando críticas a linguagem, estilo, forma e usos das palavras na referida obra, embora, evidentemente, se colocando sempre ao juízo e crivo da própria autora, como ele mesmo acentuava: "[...] cada um é dono dos seus erros e acertos." (DRUMMOND, 1959 apud AQUINO, 2000, p. 24).

$\mathrm{O}$ ato de alguém escrever para outra pessoa se reveste de uma condição íntima ou mesmo uma aventura que transborda em desvelamento de ideias e pensamentos que são compartilhados no ambiente do diálogo através da troca de missivas, momentos de leituras e aprendizagens. Assim, caberia indagar: como Zila Mamede teria recepcionado tais 
destaques, anotações, sugestões e críticas apontadas nessa missiva? A poeta teria incorporado as contribuições ao conjunto da sua obra?

Em outra missiva, de 17 de julho de 1959, Drummond sinalizava o recebimento da referida obra já publicada:

Sim. Recebi "O Arado", tomei conhecimento das novidades e das correções no texto primitivo, e achei tudo o.k. Se não mandei uma palavra a respeito, é porque tenho andado submergido em trabalhos meus e alheios [...] como eu já me havia me manifestado nitidamente sobre os "Poemas Rurais", achei que não era caso de novo pronunciamento, e daí, estava tudo em ordem, bem resolvido [...]. (DRUMMOND, 1959 apud AQUINO, 2000, p. 27).

Pelo que se pode deduzir nesta carta, após a publicação da obra "O Arado", Zila Mamede buscava também no seu leitor privilegiado, Drummond, uma resposta como avaliação da obra antes de sua publicação, constatando assim, as sugestões apontadas e, certamente, algumas delas incorporadas em sua versão final.

Na missiva de 11 de fevereiro de 1960, já acusando o recebimento da obra, o poeta Drummond respondia com alegria, entusiasmo e solidariedade ao projeto finalizado de uma produção intelectual, resultado da sensibilidade humana e da interlocução exigente e crítica:

Seu livro está aqui, encantando um velho leitor que já o conhecia bem e agora se alegra de tornar a ver o amigo. Tão puro ele é em sua aderência à terra, aos bichos, à vida natural - e tão enriquecido pelos requintes de espírito daquela que o escreveu! Obrigado pela boa visita, amiga. Senti você conversando comigo, sentado naquela poltrona [...]. (DRUMMOND, 1960 apud AQUINO, 2000, p. 29).

A relação e troca de missivas se estenderia por muito mais tempo. Nessa época Zila Mamede consolidava sua atividade intelectual nos horizontes da biblioteconomia e se dedicava a produzir a obra "Luiz da Câmara Cascudo: 50 anos de vida intelectual (19181968)". Em carta datada de 27 de março de 1967, Drummond indagava Zila sobre a relevância desse empreendimento histórico-cultural:

Sua bibliografia de Cascudo vai ser publicada? O homem merece esse esforço que você lhe dedicou e, principalmente, os estudiosos muito se beneficiarão com esse inventário de uma obra tão brasileira, que enriquece a todos [...]. (DRUMMOND, 1967 apud AQUINO, 2000, p. 43).

A obra, dado o grande investimento de pesquisa, foi publicada em 1970 pela Editora Nosso Tempo, em parceria com a Fundação José Augusto, e teve grande repercussão entre estudiosos das ciências sociais no Brasil. Segundo apresentação da própria editora, a obra "[...] custou à autora, além do trabalho extenuante, desprovido de recursos, tarefa de artesanato silencioso.” (MAMEDE, 1970, p. 3).

Entre "O Arado" (1959) e "Exercício da palavra" (1975), foram 16 anos sem uma obra de dimensão poética publicada. Nesse interregno, Zila Mamede se dedicou como 
profissional da biblioteconomia, educadora e pesquisadora, a inúmeras produções e atividades de organização de bibliotecas em várias cidades brasileiras. Contudo, vivia sua própria crise de "encantamento" e elaboração. Em obra biográfica sobre Zila Mamede, Galvão (2005) destaca o conflito dessa travessia de crise vivenciada por ela:

Passaram-se pois dezesseis anos até que voltasse a publicar poesia. Extremamente exigente com o que escrevia, passou por momentos de dúvida reforçados por timidez a poucos amigos demonstrada. (GALVÃO, 2005, p. 119).

Coube ao próprio Galvão na citada obra trazer à tona cópia de um dos raros fragmentos das cartas de Zila a Drummond, como testemunho das dificuldades e dramas existenciais vividos nessa conjuntura sombria de indefinições:

Não tenho dúvida sobre estes: tenho apenas covardia quando penso em livro [...] é um desespero, mas não consigo trabalhar o poema. Sinto-me bloqueada, com garras de ferro no pensamento. (MAMEDE, S/D apud GALVÃO, 2005, p. 120).

Em carta resposta de $1^{\circ}$ de dezembro de 1974, Drummond, além de questioná-la sobre tais conflitos, buscava também incentivá-la, propondo como principal reação o desfecho da obra que seria lançada no ano seguinte:

[...] você está precisando de, à força de outros gostarem de você, você estimar bem mais a sua poesia, tão digna e tão funda. Em sua carta e nas folhas dos poemas, quantas vezes leio a palavra medo, a palavra covardia! Que é isso, menina. Você, essa mulherzinha valente como as armas, e tão sábia no manejar o verso, ficou agora tão encucada que hesita em publicar o que escreveu, e até fala em rasgar? Rasgar coisa nenhuma, passe a limpo, emende, trabalhe sobre, exija ainda mais de si mesma, porém por favor não se entregue a esses ritos desanimados de autonegação. Que falta faz o Manuel $^{9}$ para te chamar à ordem. Eu estou chamando, sem a mesma autoridade, mas com igual ternura [...]. (DRUMMOND, 1974 apud AQUINO, 2000, p. 47).

Na missiva Drummond joga um grande peso emocional no valor da amizade cultivada para motivar Zila Mamede e, quem sabe, buscar superar uma situação complexa de desânimo, angústias e temores que a atormentava naquele momento da sua vida. A obra "Exercício da palavra" era o quarto livro de poesia e se apresentava num contexto históricocultural muito diferente dos anos de 1950, quando lançou os mais importantes livros de sua trajetória poética.

Na mesma missiva o poeta Drummond cumpria também a tarefa de leitor da referida obra ao externar suas contribuições:

Gostei muito da parte nova de "Exercício da Palavra" (bom título) em que você joga com ritmos breves e extrema economia verbal. Isso sem se desfazer nas outras composições, mais desmanchadas, digamos assim, ou menos visivelmente arquiteturais, pois em todas você é a mesma Zila poeta que sabe o que faz, e faz certo. Botei anotações mínimas em algumas páginas, mais para responder às suas dúvidas do que por necessidade crítica. De resto, crítico não sou nem desejaria ser. 


\section{Revista HIIST'TEIDBR On-line}

Apenas leitor amigo, que teve em sua prova de confiança mais uma razão de sentir: a Zila me confirma sua amizade, confiando-me seus poemas e sua penosa indecisão do momento. E isto me conforta, pois a gente quase não teve tempo de se cultivar, nesses últimos anos, e vejo que a distância não alterou o teor do nosso bem querer [...]. (DRUMMOND, 1974 apud AQUINO, 2000, p. 47).

O conteúdo da carta de Drummond remete a um sentimento e a uma realidade que caracterizam o exercício literário profissional permeado por conflitos referentes à autonomia pessoal e à profissional, bem como a necessidade de reconhecimento pelos pares e a inserção no mercado editorial. Fukelman (2014), em estudos sobre a correspondência de Clarice Lispector com Fernando Sabino, destaca a função que as cartas ocuparam no trabalho literário da referida escritora.

As correspondências tornam-se instrumento polivalente: mediam possíveis intervenções no mercado literário nacional; possibilitam trocas literárias (desde comentários sobre leituras até sugestões a respeito do que escreviam); e dão amparo emocional, crucial para a condição de duplo "exílio" (real e existencial) da autora. (FUKELMAN, 2014, p. 153-154).

Exceto pelo exílio real que é atribuído a Clarice Lispector, a narrativa epistolar de Drummond aponta para um sentimento análogo experimentado por Zila Mamede, que busca no poeta amigo apoio e orientação, numa demonstração de confiança própria às relações de afetuosidade e admiração

O livro com 31 poemas, de fato, representava uma "virada" de estilo, por isso mesmo a autora alimentava uma certa ansiedade com a recepção crítica da sua obra. Como afirmava Negreiros em seu prefácio: “[...] o livro tem o mérito de não repetir opiniões cansativas e por demais teóricas". (NEGREIROS, p. 09 apud MAMEDE, 1975). Em texto entrevista encaminhado ao "Grande Ponto", coluna do escritor e dramaturgo, Racine Santos ${ }^{10}$, Mamede afirma que adotou em Exercício da palavra alguns comportamentos da vanguarda dos anos 60:

[...] adaptando esse comportamento ao seu próprio estilo, a sua própria linguagem poética. Tenho essa coragem, a de tentar me aproximar do que é mais novo, mas tenho certeza de que não imito, ajusto a minha linguagem, tento torná-la funcional, mas procuro por outro lado, não fazer concessões aos modismos [...]. (MAMEDE, s/d, p. 4).

Essa tendência é constatada por Negreiros em seu prefácio:

Esse é o quarto livro de Zila Mamede, onde toda sua poesia foi reunida, codificada [...], projeto que delimita fases, mas quer, sobretudo, encontrar a linguagem despojada, assumindo um processo que alcança o grande valor de procurar tentar novas soluções para o verso [...] saber usar tendências as mais dinâmicas na sua poesia, sem a facilidade dos arrivismos. (NEGREIROS, p. 11 apud MAMEDE, 1975). 
Em carta de 13 de abril de 1975, o poeta Drummond recebia a versão preparada de "Exercício da palavra" e tecia comentários elogiosos à obra já encaminhada à publicação pela Fundação José Augusto:

Agora fico esperando o livro editado pela Fundação, quando é que ele chega? As soluções achadas por você para alguns poemas foram boas [...] Ou esse livro sai ou declaro guerra ao Rio Grande do Norte, país a quem quero bem porque é terra de você [...]. (DRUMMOND, 1975 apud AQUINO, 2000, p. 49).

O comentário de Drummond convergia para a escrita poética como tarefa de permanente (re) elaboração, trabalho de reescrita ou mesmo uma atividade artesanal, cuja criatividade é apenas um caminho necessário de abertura. Em resposta a Racine Santos, Zila Mamede detalha os desafios do trabalho com a palavra na referida obra:

[...] eu trabalho a ideia, inicialmente. Às vezes, penso na forma ao mesmo tempo em que na ideia. Outras vezes penso numa forma e quando executo a ideia a forma é totalmente diferente. Outras mudo propositadamente a forma. Depende de uma série de fatores [...]. (MAMEDE, s/d, p. 4).

Em carta de 09 de novembro de 1975, Drummond já atesta com entusiasmo o recebimento da obra publicada:

\begin{abstract}
Zila, amiga bem amada: "Exercício da Palavra" chegou em tempo certo, eu é que fiquei dormindo no agradecimento encantado. Livrinho pequeno? Grande. Forte livro de poesia, que você soube destilar tão bem das essências mesmas do ser. Valeu apena polir e repolir esse cristal de palavras, que você agora vem dá e sua maior cristalinidade nos inéditos, de que destaco "Tango" [...]. (DRUMMOND, 1975 apud AQUINO, 2000, p. 51).
\end{abstract}

Nesse processo de lições formadoras e orientações, como indicava na missiva o poeta Drummond, "polir e repolir" se constituiriam num permanente exercício com a palavra escrita a partir do pensado ou dito. Assim, a obra espelhava outro campo de linguagem em ascensão, adotando conscientemente, segundo Zila Mamede, "[...] alguns comportamentos da vanguarda dos anos 60.” (MAMEDE, s/d, p. 4). Em sua fala de apresentação, por ocasião do lançamento da obra, a autora afirmava:

[...] Essa exigência correspondia a uma necessidade cada vez mais forte, em mim mesma, de fazer o melhor que a mim me parecesse, de tal forma que, trabalhando e depurando duas, três, dez vezes o poema, eu não tivesse mais nada a acrescentar ou retirar [...]. (MAMEDE apud GALVÃO, 2005, p. 126).

Em $1^{\circ}$ de fevereiro de 1985, Drummond enviava aquela que seria sua última carta a Zila Mamede, tecendo breves comentários sobre a derradeira obra da poeta, "A herança", publicada pela Edições Pirata (PE) no ano de 1984:

E tenho aqui esse doce-amargo livro que é "A herança". Da qualidade da poesia não preciso dizer, você não é a marinheira de primeira viagem, e sabe bem o seu ofício. Os versos cantam, como devem cantar na verdadeira poesia. E há muitos 


\section{Revista HIIST'TEIDBR On-line}

achados verbais que atestam o dedo do artista. Mas o que me impressiona mesmo no livro é esse falar com parentes e amigos, em tom de amarga ternura, esse dom de extrair do sentimento de família, de sempre, ou de espírito, o máximo de emoção. O que há de doloroso nisto! E o que há de terno também! A família dói muito em mim, por isso me abri para os seus poemas, na ilusão de ter junto a mim os meus vivos que são os meus mortos, pois não tenho mais irmãos deste lado do mundo. Obrigado, amiga querida, pelo que me fez sentir e viver a sua poesia. Beijos do Carlos. (DRUMMOND, 1985 apud AQUINO, 2000, p. 73).

A citada obra é publicada com dedicatória aos familiares que já haviam partido e outros muito presentes em sua vida. Constitui-se, num "autorretrato", ou mesmo um mergulho emocional e memorialístico, numa condição singular de inventariar sua própria existência.

Zila também reservaria privilegiada dedicação dos escritos a alguns dos amigos que contribuíram, decisivamente, com seu amadurecimento e formação, entre os quais, João Cabral de Melo Neto, Oswaldo Lamartine e o próprio Drummond, com o poema: "Carlos Drummond de Andrade: ointent'anos".

O virtuoso período de troca de missivas é fechado com um triste e lacônico telegrama de Drummond endereçado aos familiares da poeta logo após a sua trágica morte, ocorrida em 13 de dezembro de 1985: "[...] meu profundo pesar pela perda da querida amiga Zila." (DRUMMOND, 1985 apud AQUINO, 2000, p. 75).

Gotlib (2017, p. 29), perscrutando a intensa correspondência entre Clarice Lispector e Fernando Sabino, recorre a Richard Ellmann para destacar a complexidade que envolve o gênero epistolar.

Fica um mistério, algo não nominado, que lembra a observação de Richard Ellmann (o biógrafo de Joyce e Oscar Wilde): 'O biógrafo moderno está ciente de que a carta é uma forma literária através da qual o escritor e o que recebe jogam um jogo de dissimulação e revelação. O que temos de ler na correspondência é o que não está escrito lá'. Abre-se a perspectiva para se considerar que na ficção o escritor mais abertamente se revela,livre de pressões interiorizadas.

O acesso e a leitura (d)às cartas endereçadas por Carlos Drummond a Zila Mamede permitem conhecer não apenas elementos da escrita de um e outra, mas identificar indícios biográficos das referidas personalidades da literatura brasileira.

\section{CONSIDERAÇÕES FINAIS}

Ao perscrutar as cartas de Drummond a Zila, identificam-se expressivos indícios da presença do mestre mineiro no amadurecimento da amiga poeta. Entre comentários, leituras, sugestões de uso da escrita, trocas de confidências e revelações conflituosas, essa aventura epistolar fortaleceu, principalmente, uma relação que atravessou décadas e sempre com o 
“[...] sabor inconfundível das velhas amizades", como diria o poeta. (DRUMMOND, 1980 apud AQUINO, 2000, p. 65).

Embora só tenha aparecido o registro epistolar de um dos interlocutores, por se tratar de um gênero construído colaborativamente mesmo que em tempos assíncronos de narrativa, a leitura das cartas instiga o mergulho no universo da consciência poética drummondiana e mamediana, simultaneamente. Zila Mamede faz- se presente nas cartas de Drummond. O Eu (Drummond) atualiza o Outro (Zila) em suas missivas, numa demonstração de que a relação, mesmo a distância, extrapola os limites da orientação literária e estende os fios para os laços afetivos tecidos por admiração, respeito e confiança.

Gotlib (2017, p. 29), perscrutando a intensa correspondência entra Clarice Lispector e Fernando Sabino, recorre a Richard Ellmann para destacar a complexidade que envolve o gênero epistolar.

Fica um mistério, algo não nominado, que lembra a observação de Richard Ellmann (o biógrafo de Joyce e Oscar Wilde): 'O biógrafo moderno está ciente de que a carta é uma forma literária através da qual pó escritor e o que recebe jogam um jogo de dissimulação e revelação. O que temos de ler na correspondência é o que não está escrito lá'. Abre-se a perspectiva para se considerar que na ficção o escritor mais abertamente se revela, livre de pressões interiorizadas.

E, não é de surpreender que, entre 1953 e 1985, apesar dos raros contatos pessoais, cada um tenha vivenciado a experiência do outro em diversas conjunturas, expressando, assim, uma relação duradora e afetiva. Como indica Drummond: "[...] foi bom ter carta de você contando de seu novo pouso. De biblioteca a biblioteca, meu pensamento vai assim acompanhando você e participando um pouco de sua vida de trabalho e gosto de fazer coisas, poesia e utilidade pública [...]”. (DRUMMOND,1967 apud AQUINO, 2000, p. 43).

Portanto, no contato e leitura dos textos de correspondências (cartas, bilhetes e cartões), mais do que um movimento de voyeurismo com a escrita de dimensão individual e privada, buscou-se neste estudo compreender os elos de uma formação poética, tendo sido Drummond, certamente, ao lado de outros grandes nomes, personagem fundamental e decisivo nesse processo ao longo de três décadas.

\section{REFERÊNCIAS}

ALVES, A. Silêncio, mar. A poesia de Zila Mamede nos anos 50. Natal: Sebo Vermelho, 2006.

AQUINO, M. da G. (Org.). Cartas de Drummond a Zila Mamede. Natal: Sebo Vermelho, 2000. 
BARMAN, R. J. Princesa Isabel do Brasil: gênero e poder no século XIX. Tradução Luiz Antônio Oliveira Araújo. São Paulo: Ed. da UNESP, 2005.

BOAVENTURA, C. T. Machado de Assis e José Veríssimo: aspectos da correspondência entre o escritor e o crítico. Teresa: Revista de Literatura Brasileira, São Paulo, n. 8/9. v. 34, p. 101-117, 2008. Revista do Departamento de Letras Clássicas e Vernáculas da Faculdade de Filosofia, Letras e Ciências Humanas. Universidade de São Paulo.

CAMARGO, M. R. R. M. de. Cartas adolescentes. Uma leitura e modos de ser... In: MignOT, A. C. V.; BASTOS, M. H. C.; CUNHA, M. T. S. (Org.). Refúgios do eu: educação, história, escrita autobiográfica. Florianópolis: Editora Mulheres, 2000.

CHARTIER, R. A história cultural: entre prática e representações. Tradução de Maria Manuela Galhardo. Lisboa: Difel, 1990.

FUKELMAN, C. Cartas na mesa: amizade e carreira literária em Clarice Lispector. In: FUKELMAN, C. (Org.). Eu assino embaixo: biografia, memória e cultura. Rio de janeiro: Ed. da Ed. UERJ, 2014. p. 136-158.

GALVÃO, C. Zila Mamede em sonhos navegando. Natal: Moura Ramos, 2005.

GALVÃO, W. N. “À margem da carta”. Teresa: Revista de Literatura Brasileira, São Paulo, n. 8/9, v. 34, p. 14-29, 2008. Revista do Departamento de Letras Clássicas e Vernáculas da Faculdade de Filosofia, Letras e Ciências Humanas. Universidade de São Paulo.

GOMES, A. de. C. (Org.). Escrita de si, escrita da história. Rio de Janeiro: 7 Letras, 2005.

GONDRA, J. G. Ao correr da pena: reflexões relativas às cartas de professores do século XIX. In: MIGNOT, A. C. V.; CUNHA, M. T. S. (Org.). Práticas de memória docente. São Paulo: Cortez, 2003.

GOTLIB, N. B. Três cartas de Clarice Lispector: o imprevisto. CULT: Revista Brasileira de Cultura, ano 20, n. 229, p. 28-36, nov. 2017.

LE GOFF, J. A história nova. Tradução de Eduardo Brandão. São Paulo: Martins Fontes, 1990.

LE GOFF, J. História e memória. Tradução de Bernardo Leitão. 5. ed. Campinas: Ed. da UNICAMP, 2003.

LUCAS, M. R. de. L.; RAMOS, F. R. L. (Org.). Correio literário: cartas de intelectuais no Brasil durante o século XX. Fortaleza: Editora Instituto Frei Tito de Alencar, 2013.

MACHADO, C. J. dos. S. Zila Mamede: trajetórias educativas e literárias. Campina Grande: Ed. da EDUEPB, 2010.

MAMEDE. Z. Exercício da palavra. Natal: Fundação José Augusto, 1975. 
MAMEDE. Z. Luiz da Câmara Cascudo: 50 anos de vida intelectual. Natal: Fundação José Augusto; Nova Fronteira, 1970.

MAMEDE. Z. Memória viva de Zila Mamede. Natal: Editora Universitária, 1987.

MAMEDE. Z. Navegos. Belo Horizonte: Veja, 1978.

MAMEDE. Z. Respostas à entrevista de Racine Santos para Grande Ponto. Natal, s/d. (Mimeografado).

MARQUES, M. O. Escrever é preciso: o princípio da pesquisa. 2. ed. Ijuí: Ed. da UNIJUÍ, 1997.

MELO, P. de. T. C. de. Zila Mamede: itinerário e exercício da poesia. In: MAMEDE, Z. da. C. Navegos. Belo Horizonte: Veja, 1978.

PERROT, M. Minha história das mulheres. Tradução Angela M. S. Corrêa. São Paulo: Contexto, 2008.

SILVA, J. Q. G. S. Um estudo sobre o gênero carta pessoal: das práticas comunicativas aos indícios da interatividade na escrita dos textos. 2002. 209 f. Tese (Doutorado em Linguística) - Universidade Federal de Minas Gerais, Belo Horizonte, MG, 2002.

VERONEZ, M. A escrita de si das missivas: reflexões historiográfica e literária. Linguagem: Estudos e Pesquisas, v. 19, n. 1, p. 199-209, jan./jun. 2015.

\section{Notas}

\footnotetext{
${ }^{1}$ Professor Titular da UFPB, pesquisador CNPQ/PQ2, vinculado ao Programa de Pós-Graduação em Educação/PPGE/UFPB.

${ }^{2}$ Professora Associado II e pesquisadora do Programa de Pós-graduação em Educação da Universidade Federal da Paraíba.

${ }^{3}$ Doutoranda em Educação/PPGE/UFPB e professora de Sociologia da Educação Básica do estado da Paraíba.

${ }^{4}$ Zila Mamede nasceu em Nova Palmeira, Paraíba, em 15 de setembro de 1928, e faleceu em Natal, Rio Grande do Norte, em 13 de dezembro de 1985. Formada em Biblioteconomia, foi decisiva na organização e modernização de inúmeras bibliotecas no Brasil, com ênfase à atuação na Biblioteca Central da Universidade Federal do Rio Grande do Norte, que hoje leva seu nome. Autora de diversos livros de poemas, além de memoráveis obras, como "Luís da Câmara Cascudo: 50 anos de vida intelectual" e "Civil Geometria", sobre o poeta João Cabral de Melo Neto.

${ }^{5}$ Zila Mamede nasceu em Nova Palmeira, Paraíba, em 15 de setembro de 1928, e faleceu em Natal, Rio Grande do Norte, em 13 de dezembro de 1985. Formada em Biblioteconomia, foi decisiva na organização e modernização de inúmeras bibliotecas no Brasil, com ênfase à atuação na Biblioteca Central da Universidade Federal do Rio Grande do Norte, que hoje leva seu nome. Autora de diversos livros de poemas, além de memoráveis obras, como "Luís da Câmara Cascudo: 50 anos de vida intelectual" e "Civil Geometria", sobre o poeta João Cabral de Melo Neto.

${ }^{6}$ Walnice Nogueira Galvão em entrevista à revista Teresa, ao ser interrogada sobre a supressão de trechos e nomes em cartas feita por organizadores de correspondências assume posição contrária, e destaca: "Noto uma mentalidade de voyeur no leitor de cartas, tanto quanto no estudioso de literatura, no crítico literário. A gente
} 
quer o segredinho, o diário íntimo, a carta, o trecho cortado, a gente quer os rascunhos das obras, a gente quer tudo...". (GALVÃO, 2008, p. 20).

${ }^{7}$ As cartas aqui analisadas terão em sua referência no texto a data de origem e a publicação de referência: Cartas de Drummond a Zila Mamede. AQUINO, Ma da Graça. (Org.) Natal: Editora Sebo Vermelho, 2000.

${ }^{8}$ José Simeão Leal, Diretor da Coleção “Aspectos”, do Departamento de Imprensa Nacional.

${ }^{9}$ Referia-se ao poeta pernambucano e também amigo de Zila Mamede, Manuel Bandeira.

${ }^{10}$ Coluna do Jornal Tribuna do Norte transformada em revista, sob a organização do dramaturgo e escritor norte-rio-grandense Racine Santos.

Submetido em: 09/02/2018

Aprovado em: 25/03/2018

Publicado em: 02/04/2018 